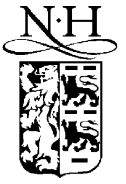

ELSEVIER

\title{
Effect of adsorbate structure on adsorption from solutions
}

\author{
Anna Deryło-Marczewska*, Adam W. Marczewski \\ Faculty of Chemistry, M. Curie-Skłodowska University, 20-031 Lublin, Poland
}

\begin{abstract}
Adsorption of benzene derivatives of various chemical properties from dilute aqueous solutions on the Norit activated carbons is investigated. The experimental systems are analyzed in terms of adsorption theory on energetically heterogeneous solids. The relations between the optimization isotherm parameters, i.e. equilibrium constants and heterogeneity parameters, and the solute properties, e.g. number, character and position of functional groups are discussed.
\end{abstract}

(C) 2002 Elsevier Science B.V. All rights reserved.

PACS: 61.43.Gt; 67.70.+n; 68.45.-v

Keywords: Activated carbon; Solute adsorption; Energetic heterogeneity; Effect of solute structure

\section{Introduction}

Adsorption from solution is a competitive process with equilibrium determined by many factors resulting from adsorbent, adsorbate and solvent properties [1-8]. The porous structure of a solid, its energetic heterogeneity (depending also on a solute) and surface chemical properties (functional groups) are the main factors influencing adsorption equilibria. The surface of activated carbon contains many active chemical groups, part of which are dissociable ones. The role of various oxygen functional groups in the mechanism of organics adsorption was discussed widely in order to relate the adsorption uptake with the changes of chemical character of carbon surface [2,9]. For adsorbate and solvent the adsorption phenomenon depends on the differences between their chemical properties, structure and interactions (mutual and with solid surface). The adsorption of various series of different organic adsorbates was analyzed to find

\footnotetext{
${ }^{*}$ Corresponding author.
}

some correlations between the sorption experimental data and the properties of adsorbate and adsorbent [4,10-19]. Many of benzene derivatives possess acidic or basic functional groups. Behavior of such adsorbate-adsorbent systems may be controlled by the solution $\mathrm{pH}$ - this phenomenon may be taken into consideration by regarding both the adsorbent surface and solute molecule as charged species [7,20,21]. Regarding the complexity of considered systems one can state that the adsorption of organic solutes on activated carbons may occur by various mechanisms that are very difficult to analyze.

In the present paper, the studies of adsorption of several benzene derivatives from aqueous solutions on activated carbons Norit RIC, RIB and RIAA are presented. The adsorbates used are all the bi-functional benzene derivatives. The type and position of functional groups differentiate solute properties. The experimental isotherms were measured over a wide range of solute concentrations at fixed $\mathrm{pH}$ and ionic strength of solution by applying the static method. The adsorption data are compared and analyzed in terms of 
the theory of physical adsorption on energetically nonhomogeneous solids. In this approach, the effect of structural heterogeneity is taken into account by its effect on the adsorption energies of a solute-adsorbent system. In this way, within the limits of this approximation, the system may be regarded and studied as one showing mainly the energetic non-homogeneity. The relations between the adsorbate structure and adsorption parameters are discussed.

\section{Experimental and calculation procedures}

The activated carbons RIC, RIB and RIAA (Norit n.v., Amersfoort, The Netherlands) were chosen for the adsorption experiment. From nitrogen adsorption/ desorption isotherms the characteristics of the studied adsorbents were determined: the specific surface area $S_{\text {BET }} \quad\left(S_{\text {BET }, \text { RIC }}=1450 \mathrm{~m}^{2} / \mathrm{g}, \quad S_{\text {BET }, \text { RIB }}=1190 \mathrm{~m}^{2} / \mathrm{g}\right.$, $\left.S_{\text {BET,RIAA }}=975 \mathrm{~m}^{2} / \mathrm{g}\right)$, the total pore amount, $V_{\mathrm{t}}$ $\left(V_{\mathrm{t}, \text { RIC }}=0.73 \mathrm{~cm}^{3} / \mathrm{g}, V_{\mathrm{t}, \mathrm{RIB}}=0.64 \mathrm{~cm}^{3} / \mathrm{g}, V_{\mathrm{t}, \mathrm{RIAA}}=\right.$ $\left.0.50 \mathrm{~cm}^{3} / \mathrm{g}\right)$, the micropore volume, $V_{\text {mic }}\left(V_{\text {mic }, \text { RIC }}=\right.$ $0.66 \mathrm{~cm}^{3} / \mathrm{g}, V_{\text {mic,RIB }}=0.53 \mathrm{~cm}^{3} / \mathrm{g}, V_{\text {mic,RIAA }}=0.45$ $\left.\mathrm{cm}^{3} / \mathrm{g}\right)$, and the external surface area, $S_{\text {ext }}\left(S_{\text {ext,RIC }}=\right.$ $\left.43 \mathrm{~m}^{2} / \mathrm{g}, S_{\text {ext,RIB }}=70 \mathrm{~m}^{2} / \mathrm{g}, S_{\text {ext,RIAA }}=25 \mathrm{~m}^{2} / \mathrm{g}\right)$. The adsorption capacity, $a_{\mathrm{m}}$, was estimated from the specific surface area and the average area occupied by a simple aromatic molecule $\left(0.35 \mathrm{~nm}^{2}\right)\left(a_{\mathrm{m}, \mathrm{RIC}}=4.29 \mathrm{mmol} / \mathrm{g}\right.$, $a_{\mathrm{m}, \mathrm{RIB}}=4.97 \mathrm{mmol} / \mathrm{g}, a_{\mathrm{m}, \mathrm{RIAA}}=6.40 \mathrm{mmol} / \mathrm{g}$ ) [22].

The adsorption from dilute aqueous solutions was measured for the following organic adsorbates: 2-, 3and 4-nitrophenol; 2-, 3- and 4-nitroaniline; 2-, 3- and 4-nitrobenzoic acid and 2-, 3- and 4-chlorophenol. The adsorption data of benzoic acid (on carbons RIAA, RIB and RIC), as well as 4-nitroaniline and 2-, 3- and 4-nitrotoluene (on carbon RIC) were published earlier [22,23]. The adsorbate properties are summarized in Table 1 [24]. The liquid mixtures were prepared with bi-distilled water and organic substances of commercially available quality (Merck, Germany; Aldrich, USA). The known amount of adsorbent was first contacted with $5 \mathrm{~cm}^{3}$ of water and degassed under vacuum in Erlenmeyer flasks and then the adsorbate solution was added. The ionic strength $\left(I=0.1 \mathrm{~mol} / \mathrm{dm}^{3}\right)$ and $\mathrm{pH}=2.2$ were regulated by adding $\mathrm{NaCl}$ and $\mathrm{HCl}$, respectively. The vessels were thermostated at $293 \mathrm{~K}$ and agitated until the equilibrium was attained. Finally, the equilibrium
Table 1

The properties of various benzene derivatives [23]

\begin{tabular}{lllll}
\hline Compound & Code & $M(\mathrm{~g} / \mathrm{mol})$ & $c_{\mathrm{s}}(\mathrm{mmol} / \mathrm{g})$ & $\mathrm{p} K_{\mathrm{a}}$ \\
\hline Nitrobenzene & $\mathrm{NB}$ & 137.14 & 87 & - \\
2-Nitrotoluene & 2-NT & 137.14 & 4.74 & - \\
3-Nitrotoluene & 3-NT & 137.14 & 3.65 & - \\
4-Nitrotoluene & 4-NT & 137.14 & 3.21 & - \\
Benzoic acid & BA & 122.12 & 24 & 4.2 \\
2-Nitrobenzoic acid & 2-NBA & 167.12 & 38.9 & 2.17 \\
3-Nitrobenzoic acid & 3-NBA & 167.12 & 18.55 & 3.45 \\
4-Nitrobenzoic acid & 4-NBA & 167.12 & 1.45 & 3.44 \\
2-Nitrophenol & 2-NPh & 139.11 & 14.6 & 7.23 \\
3-Nitrophenol & 3-NPh & 139.11 & 78 & 8.4 \\
4-Nitrophenol & 4-NPh & 139.11 & 84.8 & 7.15 \\
2-Chlorophenol & 2-CPh & 128.56 & 221.69 & 8.48 \\
3-Chlorophenol & 3-CPh & 128.56 & 202.24 & 9.02 \\
4-Chlorophenol & 4-CPh & 128.56 & 210.02 & 9.38 \\
2-Nitroaniline & 2-NA & 138.13 & 7.96 & -0.7 \\
3-Nitroaniline & 3-NA & 138.13 & 6.52 & 2.5 \\
4-Nitroaniline & 4-NA & 138.13 & 4.13 & 1 \\
\hline
\end{tabular}

concentrations were measured by using UV-VIS spectrophotometer Specord M40 (Carl Zeiss, Jena, Germany). The adsorbed amount of organic substance was calculated from the material balance. For planning the liquid adsorption experiments the equilibrium simulation procedure was used [21].

In order to take into account a strong non-homogeneity of the studied experimental systems the isotherm data for adsorption of solute from dilute solution were analyzed in terms of the theory of adsorption on energetically heterogeneous solids. The global isotherm equation may be written in the following form $[5,6]$ :

$\theta=\frac{a}{a_{\mathrm{m}}}=\int_{\Delta} \theta_{\mathrm{l}}(c, E) \chi(E) \mathrm{d} E$

where $\theta$ is the relative adsorption of organic solute over the whole surface phase, $a$ its adsorption, $a_{\mathrm{m}}$ the adsorption capacity, $\theta_{1}$ the local relative adsorption, $c$ the solute concentration, $E$ the difference of reduced adsorption energies of solute and solvent, $\chi(E)$ the distribution function of differences of adsorption energies, $\Delta E$ is the integration range.

The global isotherm Eq. (1) generates a group of isotherms, which can be presented in the form of 
generalized Langmuir (GL) equation [25]:

$\theta=\left[\frac{(K c)^{m^{*}}}{1+(K c)^{m^{*}}}\right]^{m / m^{*}}$

where heterogeneity parameters $m$ and $m^{*}$ characterize the shape (width and asymmetry) of adsorption energy distribution function, and the equilibrium constant, $K$, describes the position of distribution function on energy axis.

For the special values of heterogeneity parameters $m=m^{*} \in(0,1)$ the isotherm (2) reduces to the known Langmuir-Freundlich (LF) equation [5]:

$\theta=\frac{(K c)^{m}}{1+(K c)^{m}}$

This equation approximates very well the behavior of most adsorption systems of quasi-Gaussian energy distributions, for moderate adsorption values (e.g. $\theta \in 0.2-0.8)$ - even if the energy distribution function is not entirely symmetrical (i.e. $m \neq m^{*}$ ).

The experimental adsorption isotherms were analyzed by using the following linear form of LF Eq. (3):

$\ln \left[\frac{\theta}{1-\theta}\right]=m \ln K+m \ln c$

\section{Results and discussion}

The adsorption of ortho-, meta- and para-benzene derivatives: 2-, 3- and 4-chlorophenol 2-, 3- and 4-nitroaniline, 2-, 3- and 4-nitrobenzoic acid, and 2-, 3- and 4-nitrophenol from aqueous solutions on the carbons RIC, RIB and RIAA were studied. In Figs. 1-4 the experimental isotherms are drawn in the co-ordinates $\log a$ versus $\log c$. However, in Figs. 5-7 the adsorption isotherms of various 2-, 3- and 4-benzene bi-derivatives on RIB carbon are compared to illustrate the effect of group type and position on sorption phenomenon. For a given adsorbate series the adsorption properties of different derivatives depend on various factors: solubility, acidity, interactions (especially intramolecular or intermolecular hydrogen bonding), steric effects [7]. Regarding the complexity of studied adsorption systems it is very difficult to estimate the shares of separate effects on adsorption equilibria. Instead, we chose relatively simple parameters and properties and tried to find their significance in adsorption process.

In order to determine the isotherm characteristics for the studied experimental systems the simple linear form of LF isotherm was used. These dependencies are also presented in Figs. 1-4. One can state that quite

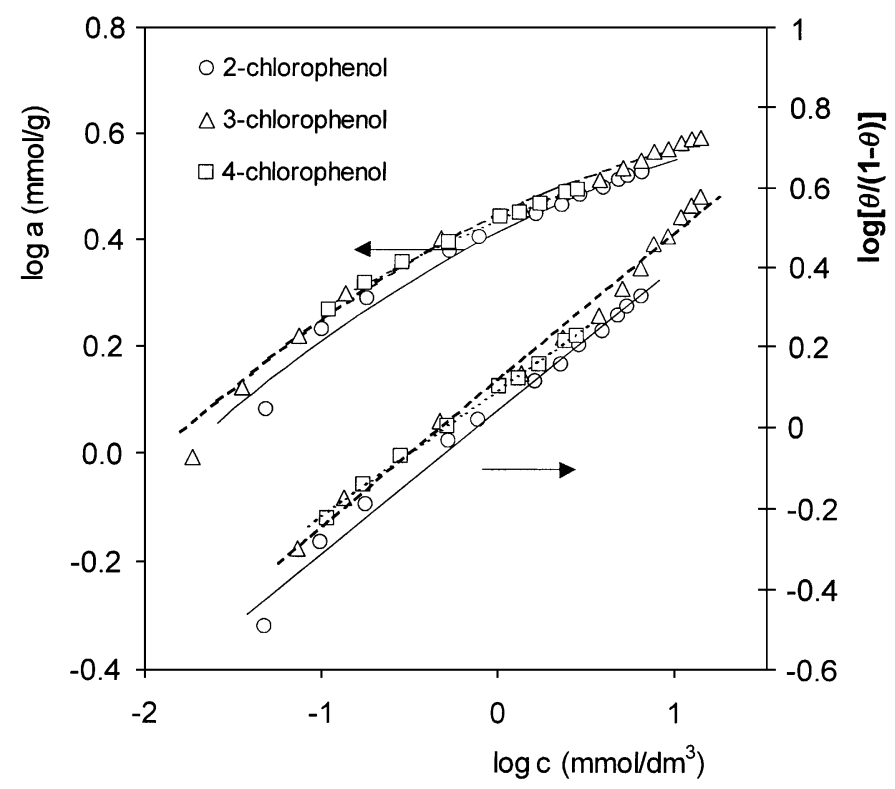

Fig. 1. The experimental data and the linear LF isotherms for adsorption of 2-, 3- and 4-chlorophenol from dilute aqueous solutions on the activated carbon RIB at $293 \mathrm{~K}$. 


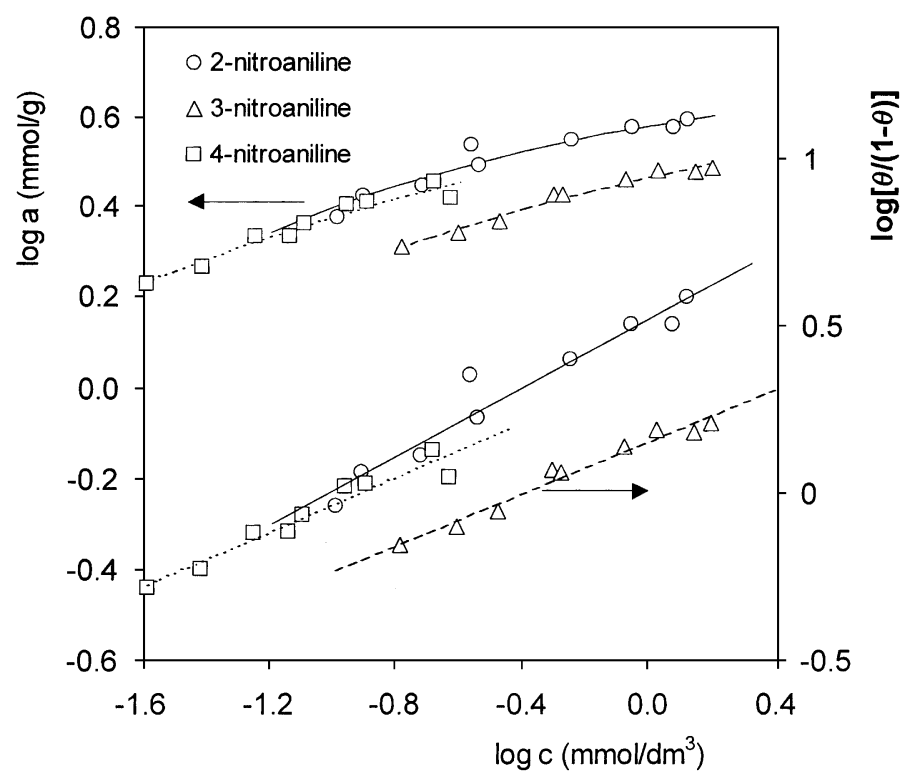

Fig. 2. The experimental data and the linear LF isotherms for adsorption of 2-, 3- and 4-nitroaniline from dilute aqueous solutions on the activated carbon RIB at $293 \mathrm{~K}$.

a good correlation is observed for all isotherms. The LF parameters are presented in Table 2. Additionally, the parameters characterizing adsorption of 2-, 3- and 4-nitrotoluene, 4-nitroaniline [23] and benzoic acid
[22] are given in Table 2. All adsorption systems show rather strong non-homogeneity effects; the heterogeneity parameter $m$ is higher than 0.5 only in the case of one system.

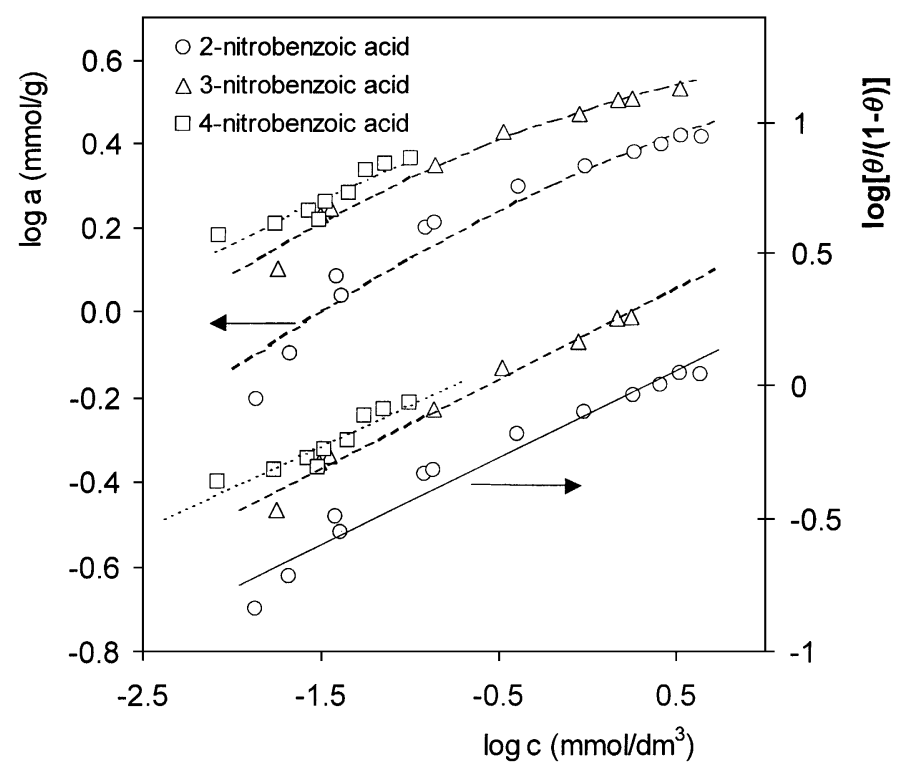

Fig. 3. The experimental data and the linear LF isotherms for adsorption of 2-, 3- and 4-nitrobenzoic acid from dilute aqueous solutions on the activated carbon RIB at $293 \mathrm{~K}$. 


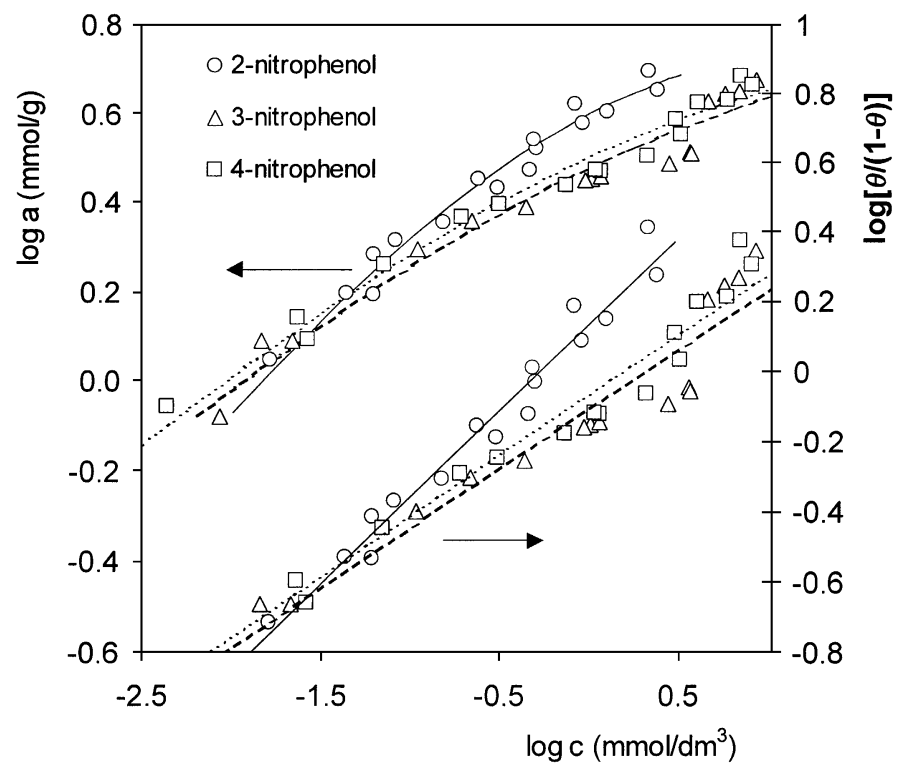

Fig. 4. The experimental data and the linear LF isotherms for adsorption of 2-, 3- and 4-nitrophenol from dilute aqueous solutions on the activated carbon RIAA at $293 \mathrm{~K}$.

Analyzing the presented dependencies and values of adsorption parameters one can conclude that distinctly higher values of heterogeneity parameter $m$ (i.e. lower heterogeneity effects) are observed in the case of ortho-derivatives. However, $m$ is usually the lowest (highest heterogeneity) for para-derivatives with values of $m$ for meta-compounds somewhere in-between. The above differences may be explained by the closeness of functional groups of ortho-derivatives (this may be "sensed" by the surface as a

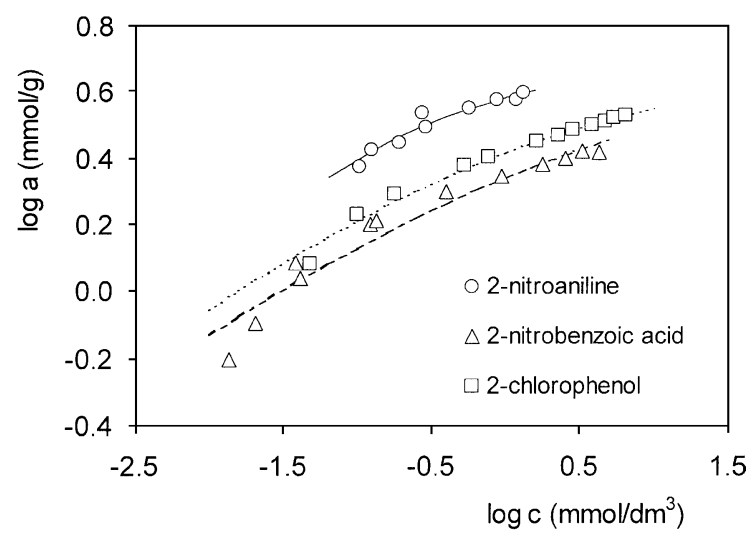

Fig. 5. Comparison of adsorption isotherms for various 2-benzene derivatives on the activated carbon RIB at $293 \mathrm{~K}$. single, even as larger, functional group) and separation of functional groups in meta- and para-positions for other solutes. Bigger size and/or larger number of groups of an adsorbate lead to a higher heterogeneity (lower $m$ ) for the same surface [26].

For the RIB carbon and acidic adsorbates (chlorophenol, nitrobenzoic acid), $\log K$ increases from orthothrough meta- to para-derivatives. This sequence is just opposite in the case of basic nitroanilines. One may conclude, that it must be a result of differences

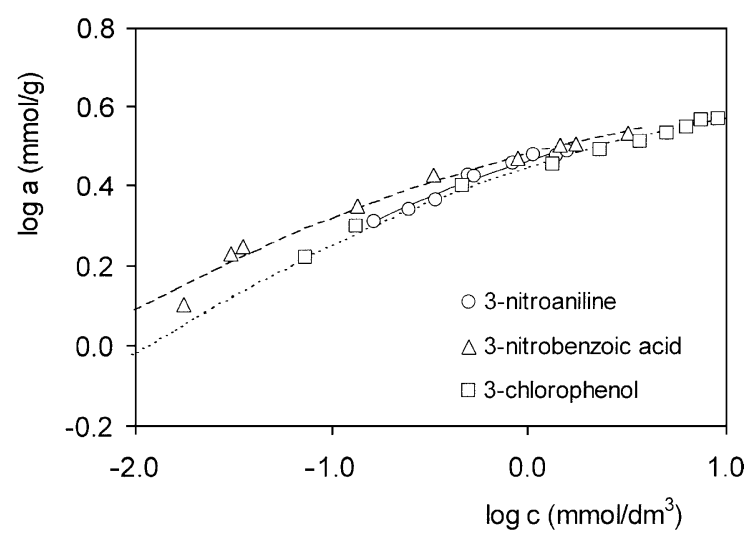

Fig. 6. Comparison of adsorption isotherms for various 3-benzene derivatives on the activated carbon RIB at $293 \mathrm{~K}$. 


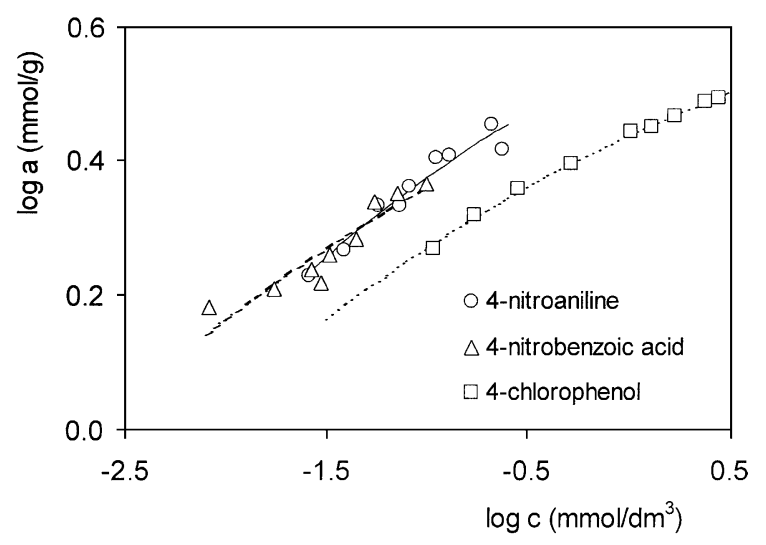

Fig. 7. Comparison of adsorption isotherms for various 4-benzene derivatives on the activated carbon RIB at $293 \mathrm{~K}$.

in interactions with various types of surface groups and changes of acidity ( $\mathrm{p} K_{\mathrm{a}}$ is usually the lowest for ortho) and solubility (usually the highest for ortho) of adsorbates.

In Fig. 8 we compared the logarithms of adsorption equilibrium constants $\log K$ with logarithms of their

\section{Table 2}

The values of parameters characterizing adsorption of organic substances from dilute aqueous solutions on activated carbons at $293 \mathrm{~K}$

\begin{tabular}{llrl}
\hline Carbon & Adsorbate & $\log K$ & $m$ \\
\hline RIB & 2-Chlorophenol & 0.12 & 0.36 \\
& 3-Chlorophenol & 0.32 & 0.37 \\
& 4-Chlorophenol & 0.29 & 0.31 \\
RIB & 2-Nitroaniline & 1.01 & 0.52 \\
& 3-Nitroaniline & 0.39 & 0.39 \\
& 4-Nitroaniline & 0.91 & 0.40 \\
RIB & 2-Nitrobenzoic acid & -0.31 & 0.33 \\
& 3-Nitrobenzoic acid & 0.59 & 0.34 \\
& 4-Nitrobenzoic acid & 0.77 & 0.31 \\
RIAA & 2-Nitrophenol & 0.28 & 0.49 \\
& 3-Nitrophenol & -0.32 & 0.34 \\
& 4-Nitrophenol & -0.19 & 0.34 \\
RIC & 2-Nitrotoluene [23] & 1.31 & 0.77 \\
& 3-Nitrotoluene [23] & 1.23 & 0.45 \\
& 4-Nitrotoluene [23] & 1.52 & 0.37 \\
RIC & 4-Nitroaniline [23] & 0.83 & 0.36 \\
RIAA & Benzoic acid [22] & -0.31 & 0.41 \\
RIB & Benzoic acid [22] & -0.21 & 0.43 \\
RIC & Benzoic acid [22] & 0.22 & 0.34 \\
\hline
\end{tabular}

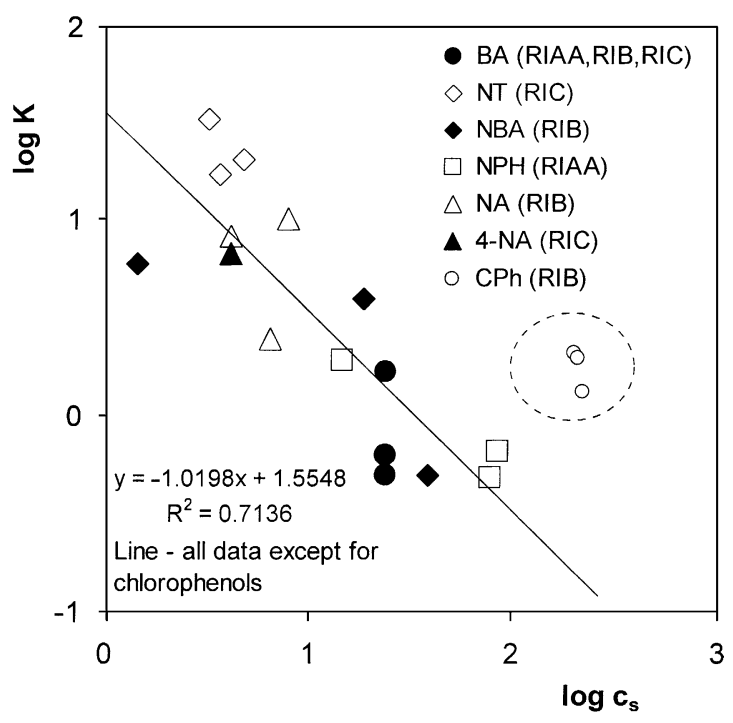

Fig. 8. Correlation between the adsorption equilibrium constant, $K$, and solute solubility, $c_{\mathrm{s}}$, for various benzene derivatives on carbons RIAA, RIB and RIC.

solubilities. Though the data scatter is not negligible $\left(R^{2}=0.71\right)$ it is at least in part due to varying carbon types-it is best visible for adsorption of benzoic acid on three carbons RIAA, RIB and RIC (black circles and Table 2). On the other hand, the slope of the regression line is -1.02 , in perfect agreement with the Traube's rule [7] (theoretically it should be equal to -1 ) i.e. for a given adsorbent $K c_{\mathrm{s}}=$ constant. It means that the main cause of variation of adsorption equilibrium constant is the varying adsorbate solubility.

In order to find what are the other factors, we first plotted the data of $\log K$ versus $\mathrm{p} K_{\mathrm{a}}-\mathrm{pH}$ being equal to $\log \{[$ acid $] /[$ base $]\}$ (Fig. 9). We chose this kind of plot, because one must remember, that equilibrium constant $K$ determined in adsorption experiment of dissociable solute may be in most cases considered as a composite value which depends on solution $\mathrm{pH}$, i.e. $K(\mathrm{pH})=$ $\left(K_{\text {neutr }} c_{\text {neutr }}+K_{\text {ion }} f_{\mathrm{q}}(\mathrm{pH}) c_{\text {ion }}\right) /\left(c_{\text {neutr }}+c_{\text {ion }}\right)$, where "neutr" and "ion" denote respective solute forms $\left(c_{\text {neutr }}+c_{\text {ion }}=c\right)[21,22]$ and $f_{\mathrm{q}}(\mathrm{pH})$ is electrostatic factor. This simple relationship is valid when the adsorbent surface is homogeneous-or is heterogeneous, but the shapes of adsorption energy distribution functions of both forms very are alike. Situation is further complicated if both solute forms interact in a 


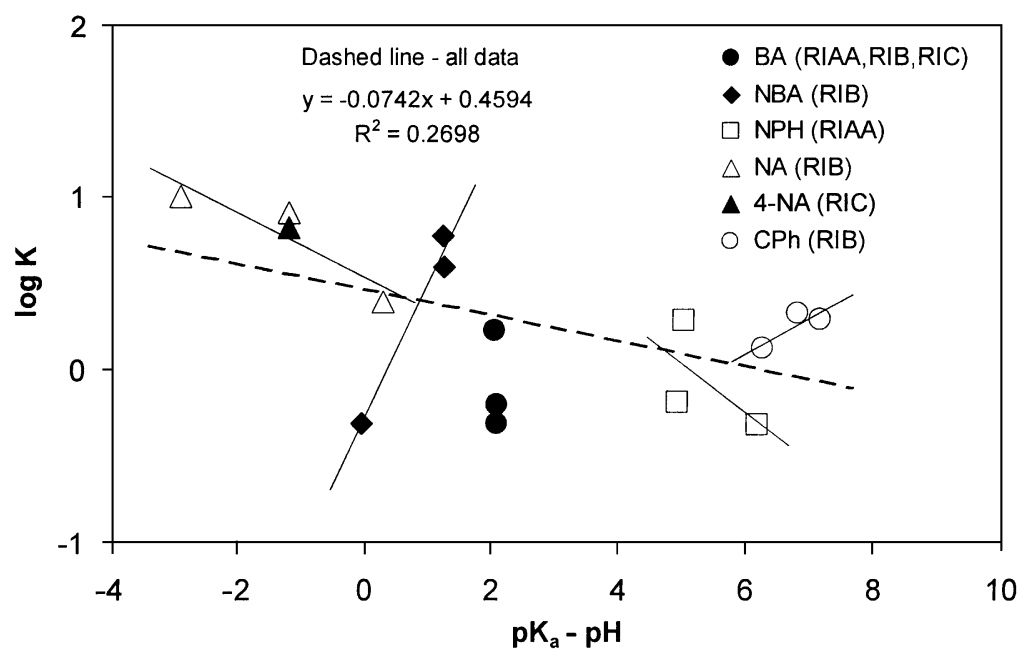

Fig. 9. Correlations between the values of adsorption equilibrium constant, $K$, and solute ionization $\left(\mathrm{p} K_{\mathrm{a}}-\mathrm{pH}=\log \{[\mathrm{acid}] /[\mathrm{base}]\}\right)$, for various benzene derivatives on carbons RIAA, RIB and RIC. Individual correlations for ortho-, meta- and para-derivatives are drawn as solid lines. A dashed line represents general correlation for all data.

different way with surface sites, e.g. acidic or basic functional groups. For low $\mathrm{pH}$ values and weak acids, $\mathrm{p} K_{\mathrm{a}}-\mathrm{pH}=\log \{[$ neutr $] /[$ anion $]\}$ is high, however, for weak bases (e.g. nitroanilines) we obtain low values of $\mathrm{p} K_{\mathrm{a}}-\mathrm{pH}=\log \{[$ cation $] /[$ neutr $]\}$. Anions at low $\mathrm{pH}$ are adsorbed moderately because usually $K_{\text {anion }}$ are smaller that $K_{\text {neutr }}$ and $K_{\text {ion }} f_{\mathrm{q}}(\mathrm{pH})$ may be small despite surface-anion electrostatic attraction (positive surface charge). The adsorption of cationic forms of weak bases is diminished by the same electrostatic factor. Data analysis shows that there are strong correlations for nitroanilines on RIB $\left(R^{2}=0.83\right.$, negative slope), for nitrobenzoic acids on RIB $\left(R^{2}=0.97\right.$, positive slope) as well as for chlorophenols on RIB $\left(R^{2}=0.73\right.$, positive slope). However, for nitrophenols on RIAA $\left(R^{2}=0.39\right.$, negative slope $)$ and global dependence for all systems shown $\left(R^{2}=0.27\right.$, negative slope) such correlation is quite weak.

Each of the plots shown in Figs. 8 and 9 exposes only one of the possible factors. From comparison of these plots, we can see that the main factor is solubility. In order to find out the influence of solute ionization on adsorption equilibrium constant, we separated the solubility factor from adsorption parameters by calculating the products of equilibrium constants and solubility, $K c_{\mathrm{s}}$. This parameter may be called a "reduced adsorption equilibrium constant" (by analogy to $c / c_{\mathrm{s}}$ being a "reduced solute concentration"). In
Fig. 10 we compare the logarithms of $K c_{\mathrm{s}}$ with $\mathrm{p} K_{\mathrm{a}}-$ $\mathrm{pH}$. The overall regression for all systems (various derivatives on various carbons) shows, that there is no single general correlation $\left(R^{2}=0.001\right)$. However, some of the individual correlations found in Fig. 9 for ortho-, meta- and para-compounds are still quite well visible. Strong correlations are present for nitroanilines ( $R^{2}=1.00$, negative slope) and for chlorophenols $\left(R^{2}=0.78\right.$, positive slope), whereas for nitrobenzoic acids and nitrophenols this correlation disappears $\left(R^{2}=0.02\right)$.

Quite logically, the increase of $\mathrm{p} K_{\mathrm{a}}-\mathrm{pH}$ for weak acids (decrease of acidity and increase of concentration of non-ionized form) causes the increase of reduced equilibrium adsorption constants, $K c_{\mathrm{s}}$. However for weak bases the increase of $\mathrm{p} K_{\mathrm{a}}-\mathrm{pH}$ (decrease of acidity of conjugate cation, increase of concentration of cationic form) it causes the decrease of reduced equilibrium adsorption constants, $K c_{\mathrm{s}}$. The common conclusion is that for ortho-, meta- and para-benzene derivatives, the reduced adsorption equilibrium constants $K c_{\mathrm{s}}$ usually increase with the increasing content of neutral form of dissociable solute.

One should note, however, that we couldn't find any data on $\mathrm{pH}$-dependencies of adsorbate solubility. In fact, physicochemical tables [23] give often contradictory values of solubility measured at "natural $\mathrm{pH}$ ", i.e. $\mathrm{pH} \sim 5-8$ (even, e.g. densities of nitroanilines 


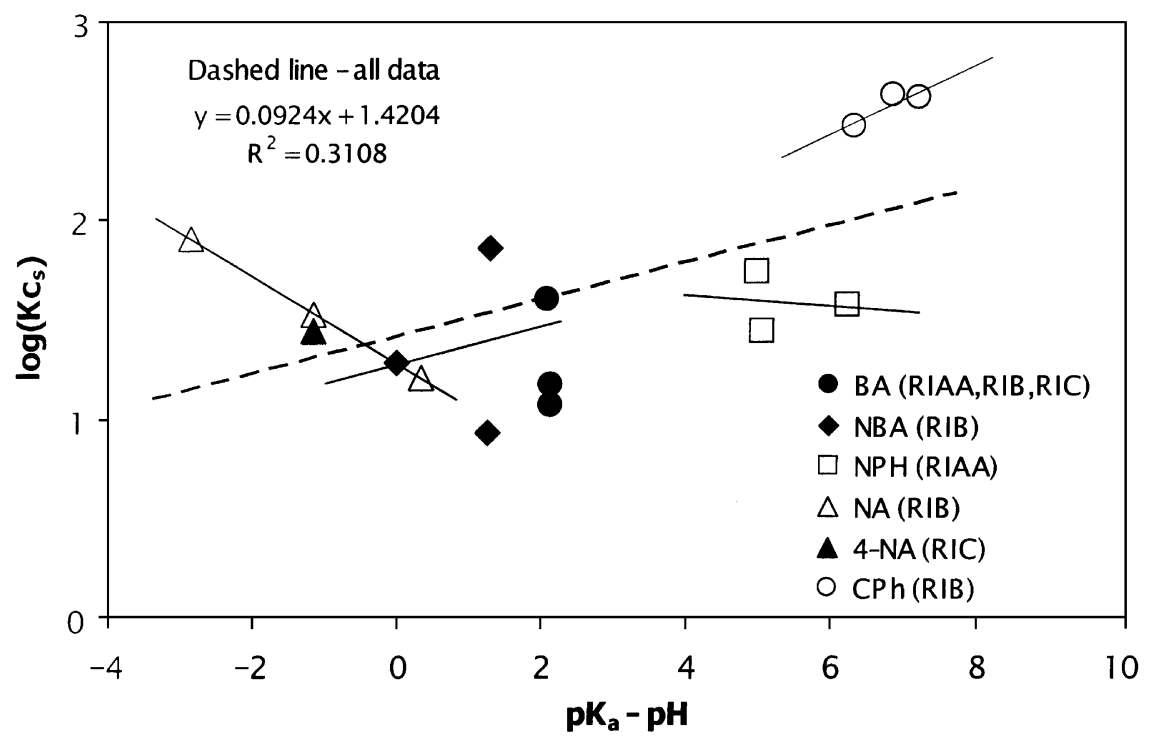

Fig. 10. Correlations between the values of $K c_{\mathrm{s}}$ and solute ionization for various benzene derivatives on carbons RIAA, RIB and RIC. Individual correlations for ortho-, meta- and para-derivatives are drawn as solid lines. A dashed line represents general correlation for all data.

mentioned by CRC and The Merck Index and other sources may be as different as 0.9 and $1.5 \mathrm{~g} / \mathrm{cm}^{3}$ ). For weak acids and our experimental conditions $(\mathrm{pH}=2.2, \mathrm{NaCl} 0.1 \mathrm{M})$, actual solubilities are only a bit lower in result of this (sodium salts are well soluble), whereas for weak bases, solubilities will be higher. However, the solubility values reported in Table 1 may still be used for comparisons of solute properties.

\section{Conclusions}

The analysis of adsorption isotherms of several bifunctional benzene derivatives (with varying type and position of functional groups) from aqueous solutions on activated carbons Norit RIC, RIB and RIAA is presented. The adsorption data are discussed in terms of the theory of physical adsorption on energetically non-homogeneous solids. The relations between the adsorbate properties and adsorption parameters are studied. The values of adsorption equilibrium constants are correlated with solute solubility and acidity. The values of heterogeneity parameters are analyzed by regarding the position of adsorbate functional groups.

\section{References}

[1] W.J. Weber, B.M. Van Vliet, in: I.H. Suffet, M.J. McGuire (Eds.), Activated Carbon Adsorption of Organics from the Aqueous Phase, Vol. 1, Ann Arbor Science, Ann Arbor, 1980, p. 15.

[2] J.T. Cookson, in: P.N. Cheremisinoff, F. Ellerbusch (Eds.), Carbon Adsorption Handbook, Ann Arbor Science, Ann Arbor, 1978, p. 241.

[3] J.S. Mattson, H.B.M.D. Malbin, W.J. Weber Jr., J.C. Crittenden, J. Colloid Interface Sci. 31 (1969) 116.

[4] J.R. Perrich, Activated Carbon Adsorption for Wastewater Treatment, CRC Press, Boca Raton, 1981.

[5] M. Jaroniec, R. Madey, Physical Adsorption on Heterogeneous Solids, Elsevier, Amsterdam, 1988.

[6] M. Jaroniec, Adv. Colloid Interface Sci. 18 (1983) 149.

[7] L.R. Radovic, C. Moreno-Castilla, J. Rivera-Utrilla, in: L.R. Radovic (Ed.), Chemistry and Physics of Carbon, Vol. 27, Marcel Dekker, New York, 2001, p. 227.

[8] A. Deryło-Marczewska, M. Jaroniec, in: E. Matijević (Ed.), Surface and Colloid Science, Vol. 14, Plenum Press, New York, 1987, p. 301.

[9] R.W. Coughlin, R.N. Tan, Chem. Eng. Progr., Symp. Ser. 64 (1968) 207.

[10] T.M. Rovinska, Koll. Zh. 24 (1962) 215.

[11] T.M. Rovinska, A.M. Koganovski, Koll. Zh. 24 (1962) 68.

[12] V. Amicarelli, G. Baldassarre, Thermochim. Acta 36 (1980) 107.

[13] T. Asakawa, K. Ogino, J. Colloid Interface Sci. 102 (1984) 348. 
[14] I. Abe, K. Hayashi, M. Kitagawa, Carbon 21 (1983) 189.

[15] I. Abe, N. Ikuta, H. Tatsumoto, in: Proceedings of the Fourth International Conference on Fundamentals of Adsorption, Kyoto, 1992, p. 333.

[16] D.R. Yonge, T.M. Keinath, K. Poznanska, Z.P. Jiang, Environ. Sci. Technol. 19 (1985) 389.

[17] F. Caturla, J.M. Martin-Martinez, M. Molina-Sabio, F. Rodriguez-Reinoso, R. Torregrosa, J. Colloid Interface Sci. 124 (1988) 528

[18] I.Z. Shirgaonkar, H.S. Joglekar, V.D. Mundale, J.B. Joshi, J. Chem. Eng. Data 37 (1992) 175.

[19] P.O. Nelson, M. Yang, Water Environ. Res. 67 (1995) 892.

[20] G. Müller, C.J. Radke, J.M. Prausnitz, J. Colloid Interface Sci. 103 (1985) 466.
[21] A. Deryło-Marczewska, Langmuir 9 (1993) 2344.

[22] A. Deryło-Marczewska, A.W. Marczewski, Langmuir 15 (1999) 3981.

[23] A. Deryło-Marczewska, A.W. Marczewski, in: D.D. Do (Ed.), Adsorption Science and Technology, World Scientific, Singapore, 2000, p. 174.

[24] Poradnik fizykochemiczny, PWN, Warsaw, 1974; The Merck Index, Merck and Co. Inc, NJ, 1996; R.C. Weast, M.J. Astle, CRC Handbook of Data on Organic Compounds, CRC Press, Boca Raton, 1986.

[25] M. Jaroniec, A.W. Marczewski, Monatsh. Chem. 115 (1984) 997.

[26] A.W. Marczewski, A. Deryło-Marczewska, M. Jaroniec, J. Colloid Interface Sci. 109 (1986) 310. 